\title{
Potential Nesting Site Analysis of Red-crowned Cranes in Kushiro Wetland using GIS
}

\author{
Hiroshi MURAKAMI and Koichi HIRATA
}

\begin{abstract}
Red-crowned cranes (Grus japonesis), once considered extinct, have been increasing in number in eastern Hokkaido, a northern island of Japan. One of the recent concerns about the cranes has been that the habitats in eastern Hokkaido may not be large enough to accommodate the increasing number of cranes. This study focuses on the breeding areas, especially the nesting sites of the cranes to develop a simple nesting site selection model using GIS so that the model will be used to help find suitable nesting areas in other parts of the island. Geographic features in 1:25,000 scale maps and existing nest location points were digitized and a nesting site selection model developed for Kushiro Wetland with GIS. Potential nesting areas analyzed by ápplying this model are small and exist only along the edge of the wetland. The result is consistent with the understanding of experts on the cranes whose breeding environment is becoming undesirable. It is expected that GIS will be also useful for the subsequent analyses required to find suitable nesting areas other than eastern Hokkaido.
\end{abstract}

Keywords: GIS, rule-based GIS, crane, potential habitat analysis.

\section{INTRODUCTION}

Red-crowned cranes (Grus japonesis), or Tancho in Japanese, inhabit Hokkaido, a northern island of Japan. They were once considered extinct about 80 years ago, because of overhunting and loss of habitats (Masatomi, 1993). However, in the 1920s, a few cranes were found in Kushiro Wetland, the largest wetland in eastern Hokkaido (Saito, 1926). Since then they have been well protected, designated as a special national natural monument by the Japanese Government, and increasing in number. The number of cranes has been counted in winter through annual crane census since 1952. In 1993, more than 600 cranes were identified in eastern Hokkaido. Recognizing the steady increase in the number of the cranes and continuing development pressure on their habitats, however, it is realistic to assume that the current breeding

Hiroshi MURAKAMI

Geographical Survey Institute, Japan

Koichi HIRATA

PASCO Corporation, Japan areas in eastern Hokkaido will be someday oversaturated for the cranes. Masatomi (1993) pointed out that the nesting sites are increasing in peripheral zones of the Kushiro Wetland where the accessibility to predators such as minks and foxes are high. High vulnerability of chicks and juveniles to such predators creates great concern about the future population of the cranes. Experts on the redcrowned cranes agree that the current number, about 600 , is not enough to maintain the species against diseases and natural disasters and at least over 1,000 cranes are necessary. In that case, new habitat areas other than eastern Hokkaido may need to be found for the cranes.

The goal of this research is to find suitable nesting areas for red-crowned cranes in Hokkaido other than eastern part using GIS. To attain this goal, the research was divided into three stages: (1) spatial analysis of existing nesting sites in the Kushiro Wetland to develop a simple model on the nesting conditions; (2) same analysis as (1) for whole eastern Hokkaido in which there exist a 
variety of natural environments from ordinary wetlands to coastal areas including open marshes; and (3) potential nesting area analysis for the other parts of Hokkaido using the model developed during the first and second stages. This paper summarizes the result of stage (1) (Murakami and Hirata, 1996).

\section{STUDY AREA AND AVAILABLE DATA SETS}

The study area of the first stage encompasses ten 1:25,000 scale topographic map sheets covering most part of the Kushiro Wetland (Fig. 1). These topographic maps were revised in 1992 and 1993. In addition to the annual crane census conducted in winter, nests are annually identified from aircraft and their locations manually plotted on 1:50,000 scale topographic maps. The positional accuracy of the nest location data is not accurately known, but it is roughly estimated not to exceed $100 \mathrm{~m}$ on the ground (Masatomi, H., personal communication, 1996). The distribution of the original nest location maps is very limited to protect the habitats from human disturbances. This project employs nest location data of 1994 re-plotted on 1:200,000 scale maps and made available to a limited number of researchers by the Environment Agency.

These maps were digitized into vector format to make a GIS database for this project. The features digitized from the 1:25,000 topographic maps include road and river networks, buildings and wetland areas. We digitized 1:25,000 topographic maps instead of smaller scale ones with comparable accuracy to the nest location maps, because the digitized data is also planned to be used for other projects.

\section{MODEL DEVELOPMENT}

Since no perfect model for nesting site selection has been developed and is difficult to develop, we developed a simple model based on a rule of thumb. Wetland areas and rivers are considered favorable for nesting while roads and buildings should be unfavorable due to possible human interference and intrusion of predators. Each nest must also be spatially separated from each other to establish the home range during the breeding season. Each road and river segment and each building were assumed to have equal influence on cranes and/or nesting conditions. Large fluctuation of the surrounding vegetation composite ratios between existing nests (Masatomi et al., 1990) suggests that nest locations should not largely depend on vegetation conditions, even though different vegetation types such as reed, sedge, alder and sphagnum are present in the Wetland. Consequently, the wetland area was assumed uniform in terms of vegetation in this analysis. The location data set of 39 existing nests found in 1994 was then used to measure the distance between the ground features and nesting sites, and between adjacent nests. In order to avoid unusual or exceptional cases of nesting sites, $10 \%$ of the nests with extreme locations were ignored for each ground feature.

The results of the measurement are shown in Figs. 2 through 5. Figure 6 shows the relationship between the Wetland and existing nests. The model thus developed has the following conditions (Ando et al., 1996):

(1) Distance from the nearest river network must be less than $265 \mathrm{~m}$;

(2) Distance from the nearest road network and the nearest building must be larger than $104 \mathrm{~m}$ and $364 \mathrm{~m}$, respectively;

(3) Distance from the existing nests must be larger than $2640 \mathrm{~m}$; and

(4) Nests must be located within the wetland area.

\section{RESULTS}

The developed model is then applied to the GIS database to find potential nesting sites in the Kushiro Wetland. The result is shown in Fig. 7, 
which indicates the following characteristics:

(1) Compared to the area of the Kushiro Wetland shown in Fig. 6, potential nesting areas in Fig. 7 are small, scattered and separated from each other and occupy only about $5 \%$ of the whole Wetland; and

(2) Most potential nesting areas are located along the edge of the wetland which is outside the protected areas and where accessibility to predators is high.

An exception is found in a circled area of the lower left part of Fig. 7. Although this area is part of the Kushiro Wetland, the natural conditions are considered different from the rest of the Wetland because the road constructed north of it has changed the water flow pattern and, as the result, made the area inappropriate for nesting sites (Masatomi, H., personal communication, 1996). This difference is clearly shown in Fig. 8 in which the locations of all identified nests from 1979 to 1994 except 1981-1984 and 1986-1989 are plotted. No nest has been identified in these years in the same circled area shown in Fig. 8. The model developed in this study was not able to distinguish this area from the rest of the wetland. The land cover data set of the Wetland derived from satellite images by Masatomi et al. (1990) does not show any difference associated with the conditions, either.

\section{DISCUSSIONS}

Since a perfect model for crane nesting site selection is unknown and will be difficult to develop as pointed out by Herr and Queen (1993), the model employed in this study is based on a simple set of rules using available data of geographic features. And there is no other data to evaluate the model and result of this study. However, even though the maximum crane population of the Kushiro Wetland is unknown, experts on the cranes believe that many cranes appear to build their nests in less than ideal locations (Masatomi, 1993). In the other parts of eastern Hokkaido, the extent of breeding areas has also been gradually expanding recently, and due to the reduction of breeding areas caused by wetland development, there have been an increasing number of new nesting sites built under undesirable conditions (Masatomi et al., 1994,1995). This tendency can be explained by the small potential nesting areas scattered along the edge of the Kushiro Wetland as shown in Fig. 7.

The significance of small potential nesting areas in Fig. 7 needs to be assessed with the accuracy of the original map and existing nest location data sets. The horizontal accuracy of ground features digitized from 1:25,000 topographic maps is less than $18.5 \mathrm{~m}$ RMSE (Murakami, 1995). The accuracy of the existing nest location data is estimated at no larger than $100 \mathrm{~m}$. If this value covers $95 \%(2 \mathrm{~s})$ of the error, the RMSE can be estimated at $50 \mathrm{~m}$. In addition, when the nest locations were re-plotted to 1:200,000 scale topographic maps, from which we digitized the data, their spatial accuracy must have been degraded with the spatial accuracy of the maps, which is within $1.2 \mathrm{~mm}$ on the maps according to the map compilation rules adopted for the map scales not larger than $1: 50,000$ (Geographical Survey Institute, 1989). Based on the same discussion as above, the RMSE of the 1: 200,000 scale topographic maps is $0.6 \mathrm{~mm}$ on the maps, i.e., $120 \mathrm{~m}$ on the ground. The combined RMSE of the nest location is then $130 \mathrm{~m}$ on the ground. This error of nest location is not small enough compared to the buffer size derived in this study. Since there are a number of potential nesting areas smaller than $130 \mathrm{~m}$ in size, such small potential nesting areas should not be considered significant.

\section{CONCLUSIONS}

GIS technology was applied to analyze nesting sites of red-crowned cranes in the Kushiro Wetland in Hokkaido, Japan. A simple model for crane 
nesting site selection was developed using existing nest location and geographic feature data sets. Potential nesting areas located by applying this model to these data sets were small and existed only along the edge of the wetland. The result was consistent with the understanding of experts on the cranes that their breeding environment is becoming undesirable.

The GIS approach was proved to be useful for helping objectively visualize the current circumstances of the Kushiro Wetland as crane breeding areas, which have been mentioned in subjective manners by crane experts.

\section{ACKNOWLEDGEMENTS}

This study was supported partly by the Environment Agency of the Japanese Government. Professor Dr. Hiroyuki Masatomi of the Hokkaido College of the Senshu University gave us useful comments and suggestions for this study. Mr. Masahiko Yoshii of the National Park Wildlife Office of Northeastern Hokkaido of the Environment Agency (currently with the Headquarters of the Environment Agency) kindly provided the 1:200,000 scale nest location maps for this project. The authors wish to thank Mr. Masayoshi Maeshima and Mr. Kei Sato for their experienced map digitizing work and Arc/Info operations in this project. Miss Emi Ando, Miss Kazumi Tsukamoto and Miss Kaori Nakamura also helped greatly for the document figures.

\section{REFERENCES}

Ando, E., Murakami, H., Hirata, K. and Sato, K. (1996) Breeding environment analysis of Tancho using GIS (in Japanese), Proceedings of the '96 Japan ARC/INFO Users' Group Conference, 41-49, Tokyo: Japan ARC/INFO Users' Group.

Geographical Survey Institute (1989) Map Specifications for 1:50,000 Scale Topographic Maps Adopted in 1989 (in Japanese), Tokyo: Japanese Association of Surveyors.
Herr A. M. and L. P. Queen (1993) Crane habitat evaluation using GIS and remote sensing, Photogrammetric Engineering and Remote Sensing, 59, 1531-1538.

Masatomi, H. (1993) The Tancho of Kushiro Shitsugen, Kushiro, Japan: Japanese Society for Preservation of Birds -Kushiro.

Masatomi, H., Ogawa, S. and Miyama, K. (1990) The relations between land-cover monitored by satellite remote sensing and distribution of the Tancho's nests in Kushiro Marsh, Hokkaido (in Japanese), J. Senshu Univ., (Hokkaido), 23, 209-223.

Masatomi, H., Momose, K., Momose, Y. and Matsuo, T. (1994) Nesting of the Tancho Grus japonesis in eastern Hokkaido, Japan, in 1991 (in Japanese), $J$. Senshu Univ., (Hokkaido), 27, 1-30.

Masatomi, H., Momose, K., Momose, Y., Matsuo, T., Koga, K., Aoki, N., Abe, S., Inoue, M. and Kanai, Y. (1995) Breeding status of the Red-crowned Crane Grus japonesis in eastern Hokkaido, Japan, in 1994, Strix, 13, 103-142.

Murakami, H. (1995) Accuracy estimation of digital map series data sets published by the Geographical Survey Institute (in Japanese), Geoinfomatics, 6, 59-64.

Murakami, H. and Hirata, K. (1996) Potential nesting site analysis of ed-crowned Cranes using GIS, International Archives of Photogrammetry and Remote Sensing, 31B4, 575-580.

Saito, H. (1926) On the Tancho in Hokkaido (in Japanese), Tori, 5, 16-19. 


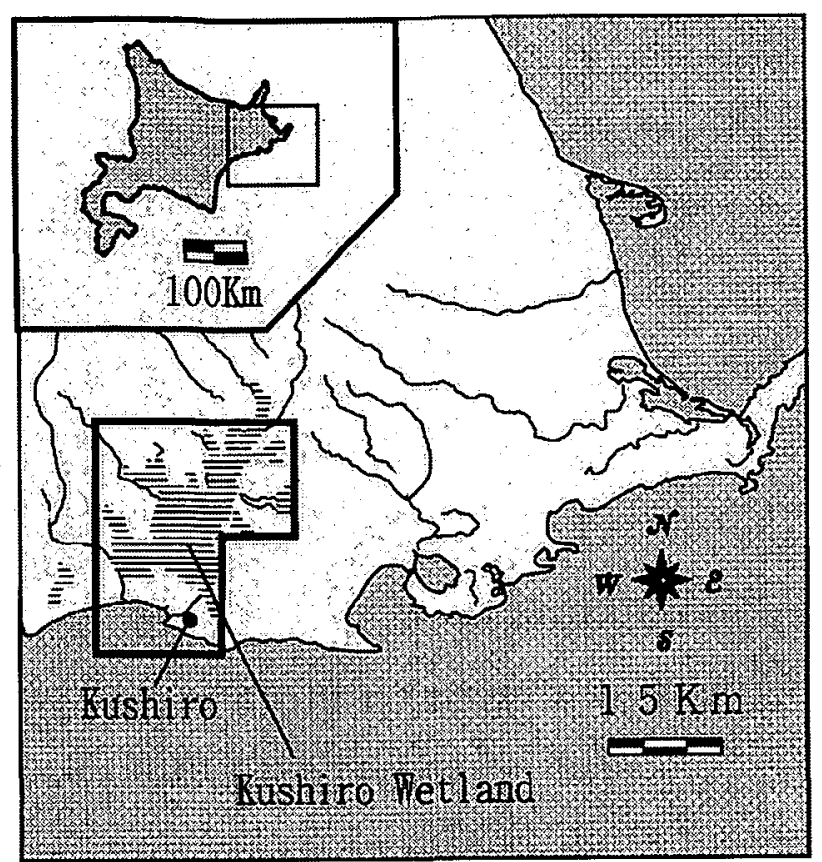

Fig.1 Location of study area

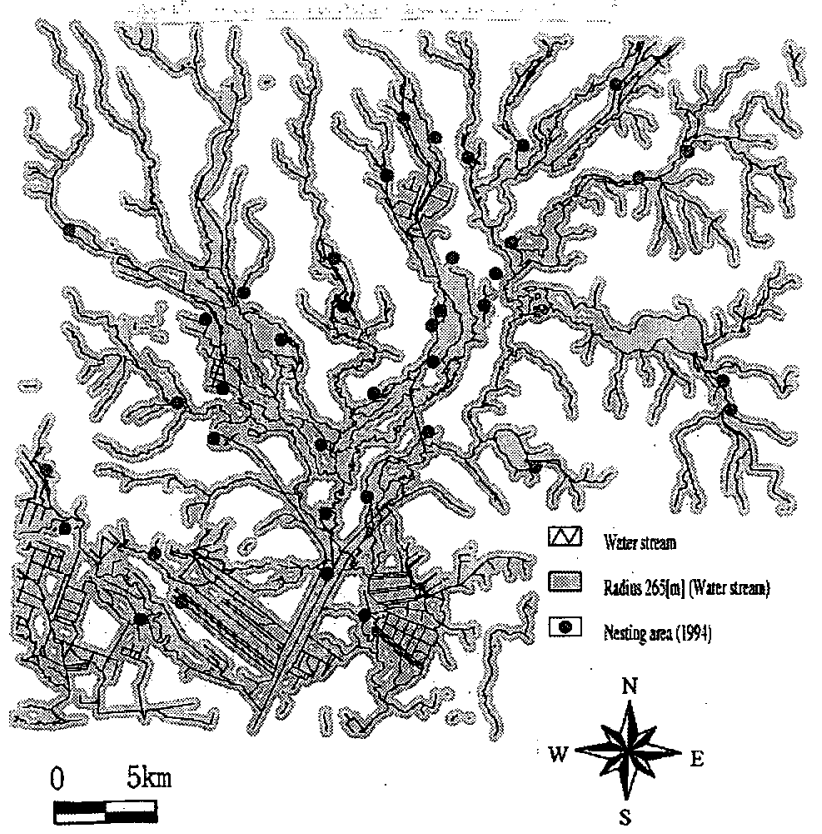

Fig. 2 Distribution of existing nests and river networks with $265 \mathrm{~m}$ buffer in Kushiro Wetland

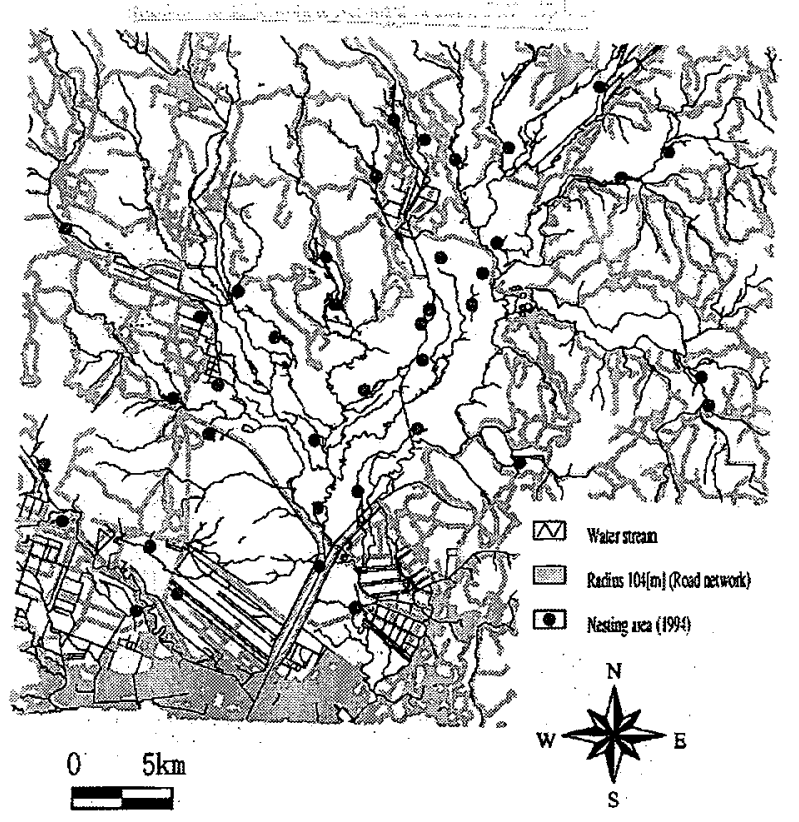

Fig. 3 Distribution of existing nests and road networks with $104 \mathrm{~m}$ buffer in Kushiro Wetland

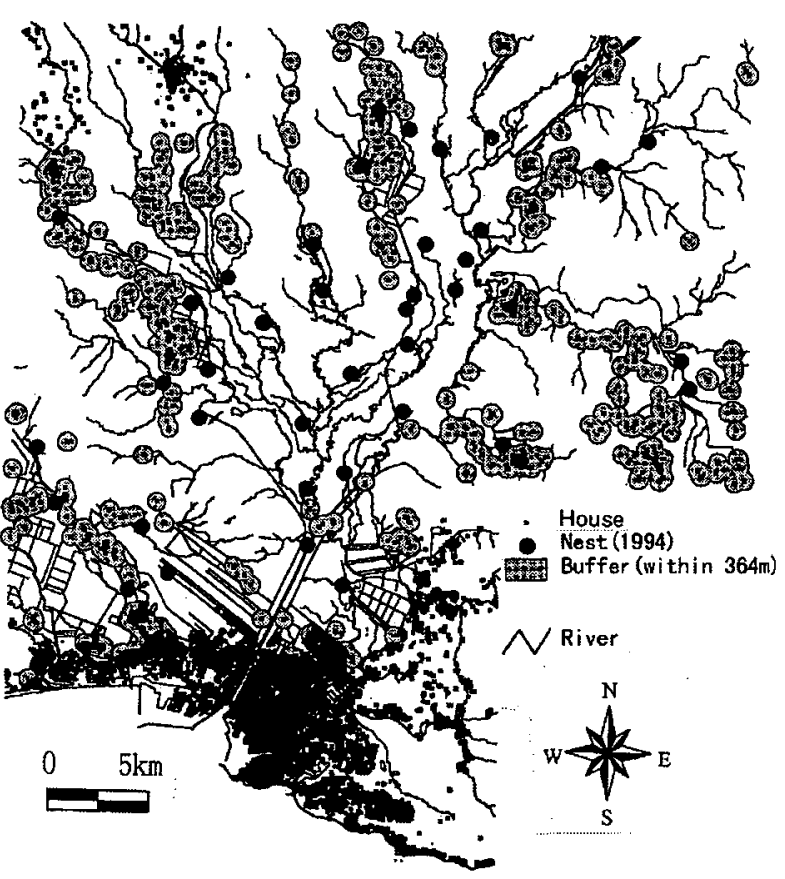

Fig. 4 Distribution of existing nests and buildings with $364 \mathrm{~m}$ buffer in Kushiro Wetland 


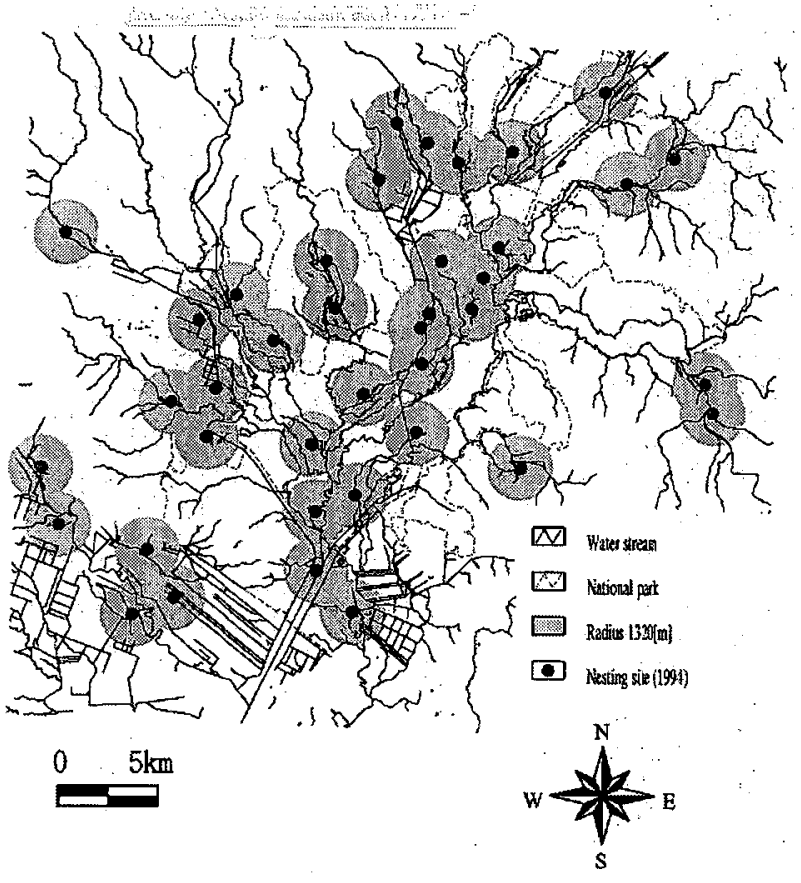

Fig. 5 Distribution of existing nests with $1320 \mathrm{~m}$ buffer in Kushiro Wetland

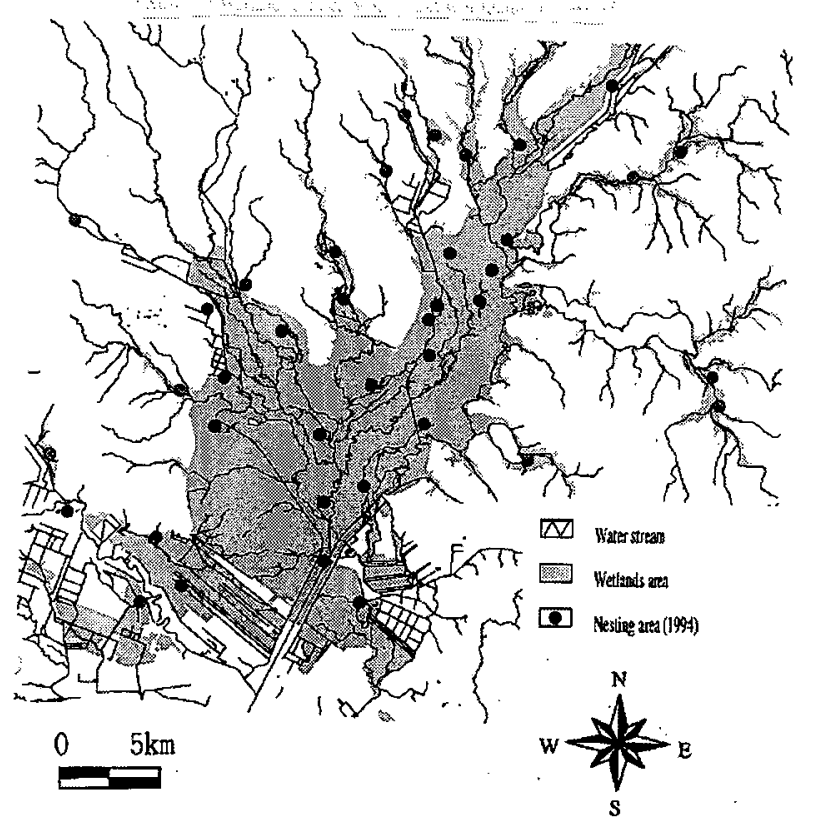

Fig. 6 Distribution of existing nests and the Kushiro Wetland area

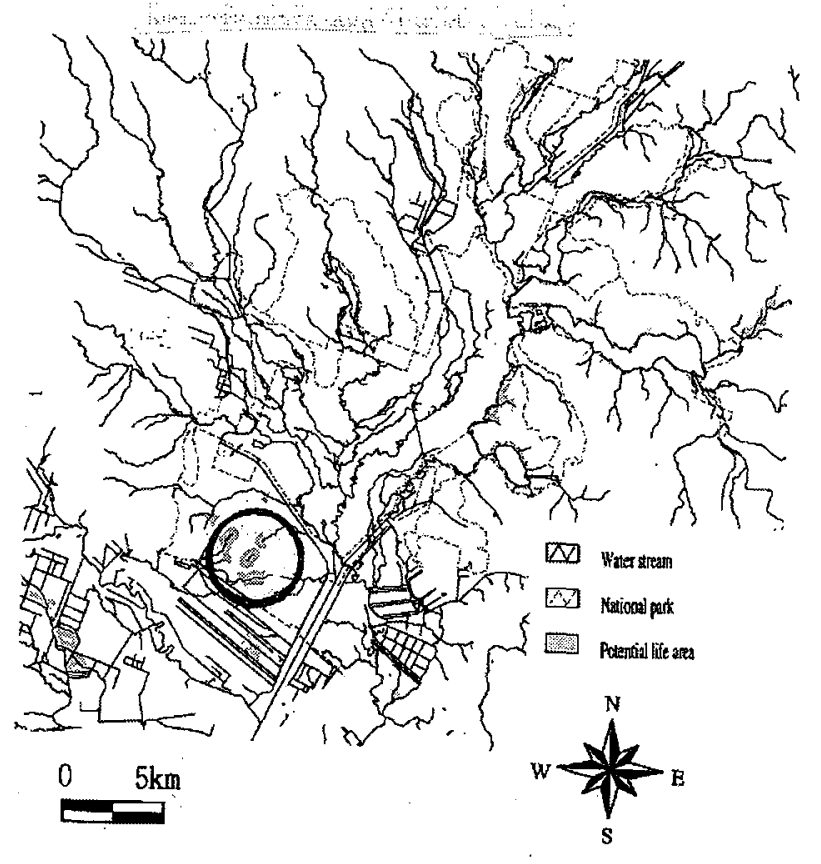

Fig. 7 Distribution of potential nesting areas extracted in Kushiro Wetland using GIS

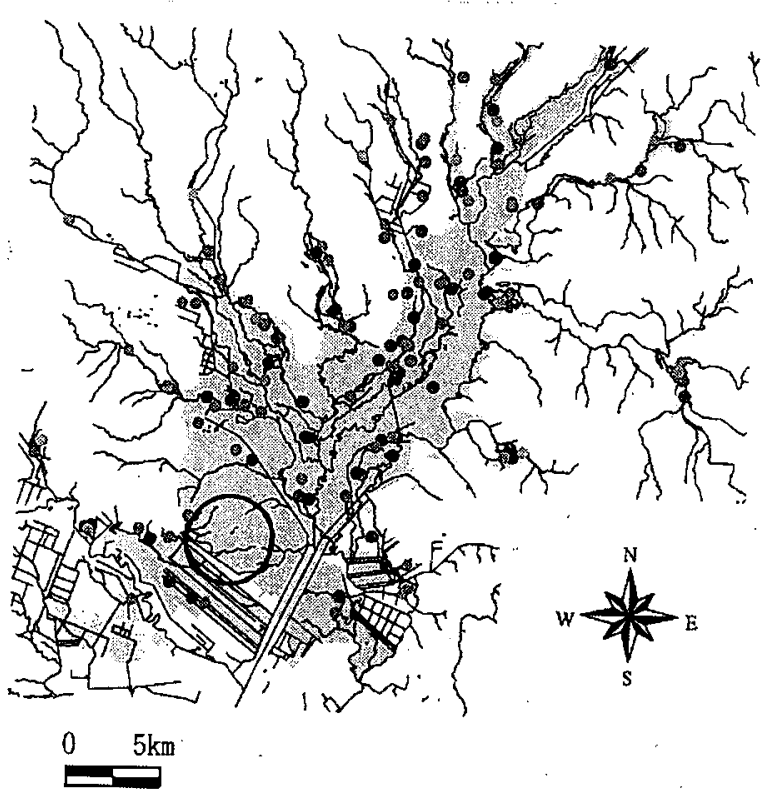

Fig. 8 Distribution of existing nests from 1979 to 1994 except 1981-1984 and 1986-1989 in Kushiro Wetland 